\title{
DECOMMISSIONING IN THE UNITED KINGDOM CONTINENTAL SHELF: DECOMMISSIONING SECURITY DISPUTES
}

\author{
Ben Holland*
}

\begin{abstract}
This article focuses on whether the decrease in the oil price will result in insufficient security to cover escalating offshore decommissioning liabilities. The annual decommissioning security process requires the calculation of an amount of security in anticipation of decommissioning. This process takes place under decommissioning security agreements, whose aim is to provide mutual protection in case one party falls into financial difficulty. The funds are held in a trust until the decommissioning is completed. This article notes that disputes have begun to arise as to whether sufficient security has already been - or ought to now be - placed in trust. This article also considers the preferred dispute resolution mechanism for such disputes, namely expert determination.
\end{abstract}

KEYWORDS: Decommissioning, Decommissioning Security Agreements, Disputes, Net Value, Net Cost, Expert Determination.

\section{INTRODUCTION}

This is the first year in which the full impact of the oil price decrease has been factored into the annual decommissioning security process. Whether sufficient security has already been or ought to be placed in trust is an area raising significant concern in the industry. Against a backdrop of historic collaboration and practical co-operation, disputes about the calculation of the amount of security that ought to apply in anticipation of decommissioning have begun to arise.

Decommissioning security agreements (DSAs) have evolved as a reaction to the extensive and continuing liability created by the Petroleum Act 1998 as amended by the Energy Act 2008. This regime provides that all current and former co-licensees will be jointly and severally liable for any decommissioning costs. DSAs were, if executed appropriately, to

* Partner, Squire, Patton and Boggs LLP UK. Email: ben.holland@squirepb.com 


\section{DECOMMISSIONING SECURITY DISPUTES}

provide the necessary mutual protection needed to ensure that, if one party to the DSA falls into financial difficulty, its security is called upon and the funds are held in a trust until the decommissioning is completed.

This article focuses on whether the decrease in the oil price will result in insufficient security to cover escalating decommissioning liabilities. As a result of current market conditions, there has been an increase in requests for data, closer scrutiny of operator projections and a heightened risk of disputes about "net value" and "net costs", which are normally resolved through expert determination.

\section{THE INCREASING FOCUS ON DECOMMISSIONING}

Decommissioning activity is gaining increasing momentum in the UK. The growth is clear from the increased number of major decommissioning projects underway which includes; the Murchison Field, for which the decommissioning programme was approved in 2014; the Brent Delta Platform for which the decommissioning programme was approved in 2015; Thames Area for which decommissioning programmes were approved in 2015 and the Leadon Field for which decommissioning programmes were approved in 2016. In addition, a number of additional decommissioning programmes are under consideration, including the Viking Satellites CD, DD, ED, GD and HD. Oil \& Gas UK has forecasted that the total decommissioning expenditure in the Central North Sea and the Northern North Sea/West of Shetland's region has increased by $£ 3$ billion with a total forecast for the industry of $£ 16.9$ billion over the 2015 to 2024 timeframe $^{1}$

With revenue projections having fallen due to the oil price decrease and cessation of production ( $\mathrm{CoP})$ dates brought forward as a consequence, previously healthy-looking security balances may now seem marginal.

\section{DECOMMISSIONING SECURITY AGREEMENTS (DSAS)}

The primary requirements for decommissioning in UK waters are set out in the Petroleum Act 1998, as amended by the 2008 Act.

\footnotetext{
${ }^{1}$ Oil \& Gas UK, 'Decommissioning Insight' (Oil and Gas UK, 2015) 6 available at $<$ http://oilandgasuk.co.uk/wp-content/uploads/2015/05/OP098.pdf $>$ accessed 9 November 2016.
} 
Under sections $29^{2}$ and $30^{3}$ of the Petroleum Act 1998, the Secretary of State may, by written notice, make a wide set of participants connected with

${ }^{2}$ Petroleum Act 1998, s 29(1) states: "The Secretary of State may by written notice require (a) the person to whom the notice is given; or (b) where notices are given to more than one person, those persons jointly, to submit to the Secretary of State a programme setting out the measures proposed to be taken in connection with the abandonment of an offshore installation or submarine pipeline (an 'abandonment programme')".

${ }^{3}$ Petroleum Act 1998, s 30(1) states: "A notice under section 29(1) shall not be given to a person in relation to the abandonment of an offshore installation unless at the time when the notice is given he is within any of the following paragraphs (a) the person having the management of the installation or of its main structure; (b) a person to whom subsection (5) applies in relation to the installation; [(ba) a person to whom subsection (5)(a) and (b) applied in relation to the installation, but who- (i) transferred the right mentioned in that subsection to another person, and (ii) has not obtained a consent required under the licence in relation to the transfer;] (c) a person outside paragraphs (a) and (b) who is a party to a joint operating agreement or similar agreement relating to rights by virtue of which a person is within paragraph (b); (d) a person outside paragraphs (a) to (c) who owns any interest in the installation otherwise than as security for a loan; (e) a [body corporate] which is outside paragraphs (a) to (d) but is associated with a [body corporate] within any of those paragraphs".

S 30(5) of the Act states: "This subsection applies to a person in relation to an offshore installation if - [(a) the person has the right - (i) to exploit or explore mineral resources in any area, (ii) to unload, store or recover gas in any area or to convert any natural feature in any area for the purpose of storing gas, or (iii) to explore any area with a view to, or in connection with, the exercise of a right within sub-paragraph (i) or (ii), and] [(b) either - (i) any activity mentioned in subsection (6) is carried on from, by means of or on the installation, or (ii) the person intends to carry on an activity mentioned in that subsection from, by means of or on the installation,] or if he had such a right when any such activity was last so carried on...".

Petroleum Act 1998, s 30(6) states: "The activities referred to in subsection (5) are-

[(a) the exploitation or exploration of mineral resources in the exercise of the right mentioned in subsection (5)(a);

(aa) the unloading, storage or recovery of gas in the exercise of that right; (ab) the conversion, in the exercise of that right, of any natural feature for the purpose of storing gas;

(ac) the exploration in exercise of that right with a view to, or in connection with, the exercise of a right within subsection (5)(a)(ii);] 


\section{DECOMMISSIONING SECURITY DISPUTES}

or interested in a particular installation jointly and severally liable for all decommissioning costs of that installation.

To deal with this extensive and overlapping liability, the industry has developed DSAs, whereby each participant agrees to deposit cash or, normally, another type of security, such as letters of credit, into a trust. That trust operates to pay the costs of decommissioning when the time comes. If a party falls into financial difficulty, the security provided is intended to be sufficient to cover that party's share of decommissioning costs.

Parties to a DSA include:

1. First Tier Participants - this group will be composed of co-venturers under a joint operating agreement (JOA). Each member of this group will provide security for the upcoming decommissioning programme.

2. Second Tier Participants - this group will be composed of those at risk of being caught by the extensive decommissioning regime. Such participants include oil \& gas companies that sold their interest in the field, often many years ago. Second Tier Participants typically remain party to the DSA to ensure that sufficient ongoing security is provided by the First Tier Participants.

3. Third Tier Participants - these are not parties to the DSA, but can, by agreement, enforce the terms of the DSA using benefits derived under the Contracts (Rights of Third Parties Act) 1999.

4. Secretary of State - if there is concern that those liable for decommissioning will be unable to discharge their decommissioning obligations; the Secretary of State may, for surveillance and enforcement reasons, become party to the DSA.

(b) the conveyance in the area so mentioned, by means of a pipe or system of pipes, of minerals got, or gas being stored or recovered, in the exercise of that right; and

(c) the provision of accommodation for persons who work on or from an installation which is or has been maintained, or is intended to be established, for the carrying on of an activity falling within paragraph (a) [to (b)] or this paragraph". 


\section{HOW DECOMMISSIONING SECURITY AGREEMENTS OPERATE}

DSAs facilitate the transfer of mature fields from established companies to smaller participants with limited financial recourses, by avoiding duplication of security. Where an interest in a field or structure is sold, the seller will be concerned about its continuing and perpetual liability to carry out decommissioning. For this reason, it is likely to require security from the purchaser. Oil \& Gas UK has produced a standard-form DSA which has recently been updated to take account of Decommissioning Relief Deeds (DRDs), together with updated guidance notes (the DSA Guidance Notes) to capture industry practice. ${ }^{4}$ The Oil \& Gas UK standardform JOA suggests that the JOA parties enter a DSA before submitting a development plan for the field.

Under such DSA, each participant in a JOA will agree to pay cash or other types of security into a trust, held until the end of the decommissioning process. The share of decommissioning costs will usually, but not always, correspond with a participant's participating interests under the JOA.

The former Department of Energy and Climate Change (DECC), now replaced by the Department for Business, Energy and Industrial Strategy (BEIS) recognises that "the over-riding aim of a DSA is to ensure that guaranteed funds will be available to cover the decommissioning costs at all times". ${ }^{5}$ However, it remains to be seen whether BEIS and/or the parties to the DSA will meet this objective. Certain industry commentators are concerned that BEIS has failed adequately to monitor the methodology underpinning the amounts paid by participants under DSAs, leading to a historic under-provision in decommissioning security.

\section{IMPACT OF THE OIL PRICE ON DECOMMISSIONING SECURITY}

A field that was economically viable when the oil price was at US\$100 per barrel is likely, at the current oil price of US\$ 30-50, to no longer be viable or only be viable for a significantly shorter estimated field life.

\footnotetext{
${ }^{4}$ Oil and Gas UK, 'Decommissioning Security Agreement (DSA), Updated October 2015 (OP021)' available at Oil and Gas UK. www.oilandgas.uk ${ }^{5}$ BEIS, 'Decommissioning of Offshore Oil and Gas Installations and Pipelines under the Petroleum Act 1998' (Guidance Notes Version 6, March 2011), Annex G, paragraph 2 .
} 


\section{DECOMMISSIONING SECURITY DISPUTES}

Decommissioning security, which could previously be spread over numerous years of ongoing production, can now only be spread over a much shorter timeframe. More security has to be put aside each year. This is occurring at a time when oil and gas operators are under significant pressure from drastically reduced revenue streams. In addition to there being fewer years of revenue from the field from which security can be drawn, decommissioning may now take place far earlier than previously estimated.

The recently established Oil \& Gas Authority ("OGA") and the UK Continental Shelf Maximising Economic Recovery (UK MER) strategy have only caused further uncertainty.

UK MER ${ }^{6}$ provides as follows:

a. in the introductory sentence: "a. all stakeholders should be obliged to maximise the expected net value of economic recoverable petroleum from relevant UK waters...c. compliance with the Strategy may oblige individual companies to allocate value between them, matching risk to reward. However, while the net result should deliver greater value overall, it will not be the case that all companies will always be individually better off...".?

b. under paragraph 7, defining the central obligation under UK MER: "Relevant persons must, in the exercise of their relevant functions, take the steps necessary to secure that the maximum value of economically recoverable petroleum is recovered from the strata beneath relevant UK waters." 8

c. under paragraph 14: "In considering the configuration required by paragraph 13, relevant persons must give due consideration to: ... b. whether or not any infrastructure already in existence could be used in such a way as to reduce costs or otherwise increase the recovery of economically recoverable petroleum from the region. This includes consideration as to whether any such infrastructure (whether proposed to be constructed or already in existence) could be so used if reasonable adjustments were to be made to it."

d. under paragraph 16: "Owners and operators of infrastructure must ensure that it is operated in a way that facilitates the recovery of the

\footnotetext{
${ }^{6}$ DECC, 'The Maximising Economic Recovery Strategy for the UK: Presented to Parliament pursuant to s 9G of Petroleum Act 1998 as amended by the Infrastructure Act 2015' (DECC, UK).

${ }^{7}$ Ibid, 2. Emphasis added.

${ }^{8}$ Ibid, 4. Emphasis added.

${ }_{9}^{9}$ Ibid, 4-5. Emphasis added.
} 
maximum value of economically recoverable petroleum from (as applicable): a. the region in which it is situated; and b. where the infrastructure is used by or for the benefit of others, the regions in which those others are situated." 10

e. under paragraph 20: "Before commencing the planning of decommissioning of any infrastructure in relevant UK waters, owners of such infrastructure must ensure that all viable options for their continued use have been suitably explored, including those which are not directly relevant to the recovery of petroleum such as the transport and storage of carbon dioxide" (emphasis added).

f. under paragraph 22: Where the OGA produces a plan "which relates to the obligation in paragraph 20 , it may identify particular pieces of infrastructure the decommissioning of which would prejudice the maximising of the recovery of economically recoverable petroleum in a region." 11

It is clear from the above provisions that operators seeking to decommission their economically unviable assets may face barriers in doing so regardless of the negative impact it may have on their financial status. This is particularly the case for offshore infrastructure that if decommissioned, may result in a decommissioning domino effect on neighbouring installations and tie(-)ins thereby decreasing the "expected net value of economic recoverable petroleum from relevant UK waters". ${ }^{12}$

For such 'critical' infrastructure, what CoP date should be used? What would the revenues be (if any) and who should bear the costs of maintaining such infrastructure? Should such potential costs even be included in decommissioning security calculations? If so, how are they to be estimated?

The magnified impact of decreased revenues, increased costs, short $\mathrm{CoP}$ timeframe and uncertain variables has, for the first time, caused those seeking to protect themselves from potential liability to carefully scrutinise both the current level of decommissioning security in place and the calculations by which the level of future security is defined.

\section{DECOMMISSIONING SECURITY DISPUTES}

The standard-form DSA requires that every year all of the First Tier Participants pay their respective share of (a) "net costs" (representing an amount equal to the best estimated cost of performing all decommissioning

\footnotetext{
${ }^{10} \mathrm{Ibid}, 5$. Emphasis added.

${ }^{11}$ Ibid, 6. Emphasis added.

12 Ibid, 2.
} 
activities multiplied by a risk factor); less (b) "net value" (representing an amount equal to expected production receipts from the field) and the amount of security that the participant has already provided.

Both net cost and net value are assessed on a net present value (NPV) basis. Where the NPV of the net cost exceeds the NPV of the net value, security is required to cover the difference. As production continues, the intention of the DSA is that the amount of security increases so that it fully funds decommissioning at $\mathrm{CoP}$.

As a result of prior beneficial market conditions, numerous industry participants consider that historically, optimistic assumptions as to future "net value" have been made. By making such optimistic assumptions of "net value", the security required to meet estimated "net costs" has been less year-on-year resulting in serious under-provision of decommissioning security. This approach, on the part of First Tier Participants, may be explained by their wish to free up cash to invest in production activities or to reduce the asset retirement obligation required so as to leverage themselves further or position themselves for sale.

Current depressed market conditions have caused Second Tier Participants (those benefitting from the security without paying in themselves) to become concerned with the adequacy of the security in place. Depressed production revenue due to falling oil and gas prices is causing Second Tier Participants to seek higher levels of security. Second Tier Participants that sold their interest many years ago are liable to contribute to decommissioning costs if the First Tier Participants default. Optional language under the standard-form DSA governs whether Second Tier Participants have a right to approve the operator's proposals or merely comment on them.

These requests for additional security from Second Tier Participants are coming at a time where falling revenues and increasing costs are impacting on First Tier Participants' ability to provide the greater levels of security sought. In addition, not all of the First Tier Participants will have the same funding profile. Parties to a JOA may legitimately take differing positions on the assumptions made by the operator. This is particularly the case for those First Tier Participants who are highly leveraged through reservesbased lending.

For these new-entrant oil and gas operators, providing suitable estimates is, on a practical note, an unenviable task. Not only is calculating accurate decommissioning estimates, no matter how carefully done, not an exact science, but smaller oil \& gas operators, who are keen to match costs to revenues, have also reduced investment in much needed personnel (such as specialist engineers) and technology (such as decommissioning software). 


\section{DECOMMISSIONING RELIEF DEEDS}

Issues with potential shortfalls in security are a particular problem for those who entered into Decommissioning Relief Deeds (DRDs). DRDs permit security to be provided on a post-tax basis. Security is, as a result, no longer being paid in at a (higher) pre-tax relief basis. Since October 2013, when DRDs were introduced, a reduction in both any previously existing decommissioning security "buffer" that resulted from payments having been made on the (higher) pre-tax relief basis, and the absolute amount of security set aside has arisen. This is, unless, of course, a higher risk factor has been applied to net costs.

A higher net cost risk factor, however, is unlikely to have been applied. First Tier Participants, incentivised to maximise cash flows, are likely, where possible, to have used lower risk factors, higher reserve estimates and other metrics to reduce the level of decommissioning security due under a DSA. Second Tier Participants may have been comfortable with lower estimates for the calculation of security due to net costs having been calculated on a pre-tax basis and making forward assumptions based on the vibrant oil and gas market at the time. The move to a post-tax calculation of net costs has exacerbated this historic under-provision of security.

The recalculation and review of decommissioning security calculations is now being carefully monitored by both co-venturers and by Second Tier Participants. There has been an increase in requests for data, closer scrutiny of projections of "net value" and "net costs", and a greater interest in the use of expert determination in the event that the participants cannot agree.

\section{DISPUTES OVER THE CALCULATION OF NET COST}

Net cost represents the best estimated cost of performing all decommissioning activities at the time at which they can be best expected to need to be performed. There is significant scope for disputes over this calculation.

\section{a. When will decommissioning occur?}

A core assumption input into the calculation of net cost is the expected date of decommissioning. The estimated date for decommissioning has a significant impact on the level of security to be provided. The hope that ageing infrastructure might find alternative economically viable uses, as some structures (particularly pipelines) could be used via tiebacks and brownfield developments, currently seems challenging in the current low oil price environment. Of course, decommissioning may now be delayed if such infrastructure is required by the OGA to 


\section{DECOMMISSIONING SECURITY DISPUTES}

be maintained in accordance with UK MER. However, there is no guarantee that this will be economical.

Other new technology such as enhanced oil recovery (EOR) could also have postponed the date of decommissioning, but this is also only made economic by high oil prices. These possible ways to reduce net cost, which could have been discounted back (through the NPV calculation) so as to reduce the amount of security required (and also to have postponed the trigger date for provision of security) are unlikely to be viable. This is significant, because these assumptions might legitimately have been included in previous calculations, made when the oil price was higher. Disputes are arising wherever these assumptions are being reversed out and falling oil prices are bringing the expected date of decommissioning forwards. Where optimistic assumptions have been made, inadequate security is likely to be provided.

\section{b. What is the scope of decommissioning?}

There are many different forms of installation. Most installations will require an individually tailored and untested method of decommissioning. With so many variables, how accurate can the "net cost' calculation be? It is common to underestimate decommissioning costs. For example, the decommissioning close out reports of the Fife, Fergus, Flora and Agnus Fields highlight that costs overran by approximately $20 \% .^{13}$

Further scope exists for disputes over whether net costs should be based on a 'left in place' basis for installations capable of attaining a derogation (allowing the offshore installation to remain wholly or partly in place rather than being disposed of on land). ${ }^{14}$ Adopting this approach would reduce net cost. BEIS guidance suggests it is likely to require the decommissioning costs for large concrete structures to be

\footnotetext{
${ }^{13}$ HESS, 'Fire, Fergus, Flora and Angus Fields: Decommissioning Programmes Close-Out Report' (HESS, Document No: 32 ADP -016).

${ }^{14} \mathrm{~A}$ limited number of installations may be eligible for derogation from the prohibition on the dumping, or leaving wholly or partly in place, of offshore installations. Derogation will only be granted where it is a preferable means of disposal than reuse, recycling or disposal on land.
} 
estimated on this basis. ${ }^{15}$ For example, such a derogation would be likely for the Brent field platforms (Bravo, Charlie and Delta) which consist of concrete gravity-based structures (GBS) weighing 300,000 tonnes each. ${ }^{16}$

Derogations may, however, become less common due to advances in technology, and if this approach changes net cost may increase significantly. ${ }^{17}$ On the other hand, concerns about the carbon budget of extensive decommissioning operations, where every component is laboriously cut up and sorted onshore, may alternatively lead to more derogations being granted. It is easy to see how there is scope for disputes as to the most appropriate estimate to be used.

\section{c. What is the proper risk factor to apply?}

The Oil \& Gas UK standard-form JOA provides for the use of a risk factor in the security calculation. This is to provide a degree of caution against possible rises in decommissioning costs. ${ }^{18}$ Net cost estimates will usually be prepared on a P50 basis. This assumes that there is an equal chance of there being under-spending or over spending as against the costs estimate. The risk factor reflects uncertainties about the net cost estimate. The risk factor may not always have been calculated, or updated, in a fully statistically rigorous manner. These uncertainties should reduce with time as the operator obtains a better understanding of these costs, and optional language in the DSA allows the contingency to be increased or reduced in a stepped process. Presently, the ease with which this variable can legitimately be changed is making it a target for attention and a prominent source of disputes.

\footnotetext{
${ }^{15}$ BEIS (n 6) Annex F para14.

${ }^{16}$ Oil \& Gas UK, Activity Survey (Oil and Gas UK, 2015) 69 available at $<$ http://oilandgasuk.co.uk/wp-content/uploads/2015/07/EC044.pdf $>$ accessed 9 November 2016

${ }^{17}$ Oil \& Gas UK, Decommissioning Security Agreement Guidance Notes (March 2009), 38.

${ }^{18}$ Ibid, 39.
} 


\section{DISPUTES OVER THE CALCULATION OF NET VALUE}

Net value represents the best estimated production and other receipts from the field for so long as it is estimated that the field will remain in production. There is significant scope for disputes over this calculation.

\section{a. What oil and gas prices to use?}

Fluctuating oil prices will have a significant impact on net value. Regular recalculations may lead to periodic changes as oil and gas prices rise and fall. Assumptions as to future oil and gas prices should be clearly stated in the DSA. ${ }^{19}$ Published indices for oil and gas prices will need to be agreed. Any gas price indexation formula contained in any existing gas sales contract should be used when calculating future gas revenue. ${ }^{20}$

Essential to this calculation is the date on which production will cease. With so many variables, even slight adjustments can give rise to very significant variances between the parties. Since the introduction of DRDs, net revenues and net costs are normally inputted on a post-tax basis. This includes royalties, corporation tax/supplemental charge, and any PRT that is applicable. Recent changes to these taxes will need to be taken into account. Net value does, however, also take into account any tax relief or grants given or expected to be given unrelated to the costs of decommissioning. The operator is required to perform two calculations, one with and one without the effect of the relief.

\section{b. What reserves data should be used?}

Optional language under the standard-form DSA governs whether only reserves estimates approved by the Joint Operating Committee appointed under the JOA to operate and manage the licence area are to be used to calculate net value, whether the operator's best estimates, acting as a reasonable and prudent operator, are adequate, or other alternatives. ${ }^{21}$ Commonly, newer entrants into the UK Continental Shelf (UKCS) will seek to maintain the level of reported reserves.

\footnotetext{
${ }^{19}$ Ibid.

${ }^{20}$ Oil \& Gas UK (n 17) 39. However, see below in relation to concerns as to confidentiality.

${ }^{21}$ Oil \& Gas UK, Industry Model Form Decommissioning Security Agreement (September 2013) Appendix 5 paragraph 7.10. See also Oil \& Gas UK (n 17) 39.
} 
There is concern that this may lead to the reserves estimate used in the calculation of net value being optimistic, which would result in the understatement of security. Without clear drafting, there is significant scope for disputes on these assumptions.

\section{c. How to account for tiebacks and other revenue?}

Many fields receive significant revenues from tariff and other receipts from third parties, such as tiebacks. As these form revenue from the field, absent express provision in the DSA to the contrary, they should be included. A dispute may emerge as to the degree of certainty required that these receipts will accrue. On one extreme, it is arguable these receipts should only be taken into account in situations where send-or-pay arrangements ensure that such tariff income is secured. On the other, such tariff income can be taken into account even though no agreement has been concluded, or where such agreement has been concluded but is of only a limited duration, so long as there is no other route to export the tieback. The standard-form DSA contains options to address these alternatives. ${ }^{22}$

\section{EXPERT DETERMINATION UNDER DECOMMISSIONING SECURITY AGREEMENTS}

Under the Oil \& Gas UK's standard-form DSA, the cost estimation based on the foregoing forms an important part of an operator's decommissioning schedule and budget ('the Proposed Plan'). The operator will submit the Proposed Plan for approval under the JOA. Disputes may be referred to determination by an expert, if:

- the Proposed Plan submitted and/or performed by the operator is challenged;

- the operator fails to produce the Proposed Plan or perform the cost estimation; or

- the operator's determination that decommissioning has been completed is challenged.

${ }^{22}$ Oil \& Gas UK (n 17) 19. 


\section{DECOMMISSIONING SECURITY DISPUTES}

An expert is also engaged when the cost estimation performed by the operator needs to be independently reviewed, even where no dispute exists between the parties to the DSA. To address this last issue, the standardform DSA provides options that allow: (i) for a review of the net cost, net value and - where a DRD applies - PRT relief, calculations by an expert at regular intervals; or, alternatively, (ii) to have less frequent reviews initially followed by annual reviews later in the field life. A provision that a review is triggered if the operator believes that there has been a change in net cost or net value over an agreed tolerance may also be included. The likely time scales for these steps?]

\section{a. Identifying the right expert}

As decommissioning involves a variety of specialised and technical stages, any expert chosen may need assistance from multiple specialist disciplines such as reservoir engineering, offshore engineering, process engineering, drilling, subsea contractors, heavy-lift/barge contractors and disposal/refurbishment contractors. The standard-form DSA provides for this and allows the expert to obtain technical and legal advice.

If multiple expert disciplines are engaged, the expert will need to rely on and assess the views of several other experts, not just rely on his own qualifications and experience. These views would all need to have been commissioned ${ }^{23}$, provided to and then considered by the expert before the preliminary decision can be released. Delay in any of the technical elements would prevent further progress.

It may also be hard for the parties to have confidence that the expert even with this technical assistance, can manage all technical and procedural aspects. This is particularly the case if any party is seeking to elongate the process, for example by referring the expert to greater and greater volumes of documents that are said to be relevant as, without express direction from the expert, time bars to control or prevent this will not exist.

In the construction industry, where multiple specialisms are often required, a trend towards the appointment of legally qualified adjudicators rather than those with engineering qualifications has

${ }^{23}$ Commissioned by the expert (normally with the approval of the parties in dispute). 
evolved. Given the similarities, it shall be seen whether the offshore decommissioning industry finds it preferable to appoint a legally trained expert possessing relevant UKCS decommissioning experience, who can request technical assistance from relevant disciplines. The legal and procedural expertise, for example familiarity with hearing the parties, determining questions about admissibility of documents, setting submission deadlines and weighing up competing evidence may be preferable to assist good governance of the procedure in complex multiple disciplinary cases.

\section{b. Appointment of the expert}

Following any required negotiations stipulated in the DSA, a reference to an expert can be made. For challenges to the Proposed Plan (but not for other challenges), the standard-form DSA limits the right to refer the matter to the expert to the party objecting to the Proposed Plan (the "Objecting Party"). This might present difficulties for the operator who would not appear to have the right to refer the matter to the expert should the Objecting Party fail to do so nor absent either unanimity between the parties or determination by the expert, should the Proposed Plan become approved. It may be necessary to apply to the court for an order that the Objecting Party refer the matter to the expert or, in default, be deemed to have done so. Conversely, under the standardform DSA only the operator and not the other parties to the DSA can submit the cost estimation for independent periodic review. However, if the operator upon notice to do so fails promptly to comply, any other party to the DSA may itself refer the cost calculation to the expert.

The standard-form DSA contains options for appointment of the expert; either the expert is selected by unanimous vote of the parties to the DSA or each party to the DSA will nominate three candidates who are ready, willing and able to act. Those candidates will then be scored by all parties to the DSA in order of preference. The expert need not be an individual person - a firm or company can be appointed and the expert may not have "any financial or personal interest in the result". This restriction is very wide and does not allow for nominal shareholdings or for the expert to have financial connections to the parties. Coupled with the absence of immunity from suit, this may deter acceptance of the appointment. Many candidates with experience of decommissioning are likely to work for the main offshore contractors and connections to some of the parties in dispute may be probable. If agreement on the selection of the expert is not possible within 10 


\section{DECOMMISSIONING SECURITY DISPUTES}

business days, the standard-form DSA allows any party to the DSA to apply to the President of the Energy Institute to appoint the expert. The Energy Institute is a reliable and effective appointing authority.

\section{c. The scope of the expert's power}

Expert determinations, despite being capable of quickly and effectively resolving technical disputes, do not without specific provisions to the contrary require:

adherence to rules of natural justice such as the right to a hearing;

the expert to come to decisions within (rather than outside) the range suggested by the conflicting parties; or

the expert to be independent of the parties.

Unless agreed otherwise, which for obvious reasons it often is, decisions of experts are binding even in the presence of fraud or manifest error. Decisions of experts are also binding in instances where the expert sets about answering the wrong question. This introduces a degree of uncertainty in the process. The standard-form DSA seeks to limit this, by requiring that an Objecting Party express a stated written objection. In any challenge to the Proposed Plan (but not the operator's determination of completion of decommissioning), the expert must consider and determine this area of concern. The expert cannot step beyond the scope of this challenge in order to re-determine other elements. Limiting the expert in such a way also seeks to limit the cost of the expert process. In practice, parties may seek to raise additional statements of objections at a later stage in proceedings. Judicious use of the expert's power to control the procedure of the determination will be necessary in deciding whether supplemental statements of objections are permissible and within what time frame.

\section{d. Procedural matters for determination by the expert}

The standard-form DSA suggests that the parties to the DSA agree carefully defined assumptions which the operator must apply in drawing up the Proposed Plan and which the expert must also follow. These may be contentious and will be subject to individual negotiation between the parties to the DSA. In addition to the assumptions, it is 
common practice in expert determinations for an expert and all those appointing him to sign terms of reference further specifying the expert's obligations and remuneration.

In relation to documents, a significant hurdle to overcome in practice is the task of supporting the operator's assumptions with corroborative material, much of which will be confidential. Revealing information about gas sales prices and day rates to other industry participants might also infringe competition law. Unlike arbitration, it is not fatal to the integrity of an expert determination for the parties in dispute to agree to provide documents to the expert without copies to other parties; however this may not be an ideal solution in many cases due to such unilateral communications undermining confidence in the fairness of the expert process.

\section{e. Timing}

Very speedy determination is envisaged under the standard-form DSA. It is desirable for any reference to the expert to be completed in time to allow security to be replaced before existing security expires otherwise, interim invoices may need to be raised. The expert must notify the operator of his preliminary decision within 30 business days of acceptance of his appointment. The parties will then be given 10 business days to make representations. The expert must, having taken account of such representations, reach his final decision within 30 days of notification of his preliminary decision to the operator.

There is potential for references to an expert to have a very broad scope. The timings envisaged may not, however, be feasible, particularly for large or multi-installation assets, or for the review of the first cost estimation for the installation.

\section{f. The expert's determination}

The determination can be valid even if only a simple value or date (as appropriate) is determined, unless a reasoned determination has been agreed to be given. If the expert determines that greater security be paid than estimated by the operator, that additional security is required to be paid. 


\section{DECOMMISSIONING SECURITY DISPUTES}

\section{g. Costs of the expert determination}

Options exist in the standard-form DSA for payment of the expert's fees and expenses depending on the nature of the dispute being referred. The starting premise, however, is that the Objecting Party pays. Options also exist in relation to the recovery of a party's own legal and other costs, which will be the subject of individual negotiation.

\section{CONCLUSION}

Decommissioning security is becoming a topic of increased concern. Given current market conditions, unexpected levels of additional decommissioning security may significantly impact participants' financial capabilities. This is particularly in respect of highly leveraged new entrants.

There is much scope for disagreement over the amount of security that is contractually required. Uncertainty surrounding the accuracy of the variables involved in calculating decommissioning security has increased due to the fall in market prices. Participants are more likely to take different positions on the inputs and accuracy of all the variables involved.

Larger and smaller participants may now have diverging incentives. The ability of many participants to access the necessary funding is in doubt. Sensitive commercial negotiations are being undertaken, and securing the unanimous approval from all First and Second Tier Participants of the amounts of decommissioning security to be paid is now harder to achieve. All this is resulting in the dispute resolution procedures governing decommissioning security being put to the test. 